\title{
Besser sein als Doc Google
}

\section{Christina Aus der Au}

Prof. Dr. theol., Mitglied der Redaktion Ethik

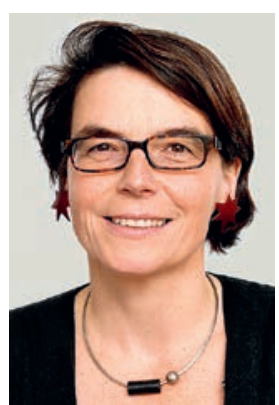

Das Stichwort «ADHS» ergibt bei Google über 5 Millionen Treffer, die Begriffe «Depression» und «Jugendliche» fast ebensoviel. Man findet auch Bilder dazu - Cartoons, Fotos, Statistiken. «Kind + psychisch krank + Symptome» ergibt über 23 Millionen Treffer, während das Ganze auf Englisch über 160 Millionen Ergebnisse zeigt.

Eine unglaubliche Fülle an Informationen für besorgte Eltern, die soeben eine Diagnose von ihrer Schulpsychologin erhalten haben. Und natürlich kommen sie nach Hause und googlen nach den Begriffen, mit denen ihr Kind - wie vorsichtig auch immer - diagnostiziert wurde. Dr. Google redet mit. Und wer will es den Menschen verdenken, dass sie sich ihre eigenen Informationen holen und dass sie umgekehrt ihre eigenen Erfahrungen ins Internet stellen. Erfahrungen mit Ärzten, mit Psychologinnen, mit Krankheiten.

Eine Freundin von mir wird Schulpsychologin. Für ihre Masterarbeit stellt sie sich genau dieser Situation. Was finden Eltern - oder auch Jugendliche - im Internet, wenn sie sich über psychische Krankheiten informieren? Womit werden sie konfrontiert, wenn sie entsprechende Begriffe eingeben? Welche sachlichen Informationen erscheinen, aber auch welche Verschwörungstheorien, welche tröstlichen und welche erschreckenden Krankheitsgeschichten werden im Internet erzählt?

Und so googelt sie sich durch einen Wust von Seiten hindurch, durchforstet Chats und analysiert Bilder. Immer mit der Frage: Was haben Eltern gesehen und gelesen, bevor sie das nächste Mal beim schulpsychologischen Dienst zum Gespräch kommen? Sie muss gleichermassen Laie sein wie auch Expertin. Worauf würde sie als besorgte Mutter ansprechen? Was würde sie weiterverfolgen? Und wie beurteilt sie diese Seiten als Psychologin? Was ist haarsträubender Mist, was ist informativ, und was ist gefährlich? Und wie kann sie diese Unterschiede vermitteln?

Das Ganze zur Kenntnis zu nehmen ist dabei das eine. Sich dann für entsprechende Fragen und Gespräche zu wappnen das zweite. Aber sich dann als Verantwortliche für den schulpsychologischen Dienst zu überlegen, wie sie im Internet präsent sein können, damit ihre Seiten mindestens ebenso schnell erscheinen und für ratlose Jugendliche und Eltern eine bessere Hilfe sein können, das ist eine Herausforderung, auf die sie jedenfalls im Studium nicht vorbereitet wurde.
Dabei geht es gar nicht darum, attraktive Seiten zu programmieren. Dafür gibt es ebenso Expertinnen und Experten wie für die fachkundige Information selber. Die Schwierigkeit liegt darin, dass man über mehrere Fronten hinweg denken muss. Professionelle Expertin sein, sachliche und differenzierte Informationen vermitteln und gleichzeitig im Wettbewerb stehen mit Informationsanbietern von irgendwoher, die eindeutiger und einfacher oder aber persönlicher und damit vertrauenserweckender daherkommen.

Tom Nichols, Professor für National Security Affairs, beklagt in einem einflussreichen Buch den "Tod der Expertise» [1]. Wenn ich als Mutter im weiten Ozean des Internets Abermillionen von Informationen und Erfahrungsberichten finden kann, weshalb soll ich dann ausgerechnet dieser einen Seite glauben, wenn doch ganz unterschiedliche Positionen mit Doktortiteln daherkommen? Wenn es zu jeder Lehrmeinung zig Gegenpositionen gibt, warum sollte ich mir nicht diejenige zu eigen machen, die zu meinem Weltbild passt? Aus einer gesunden Skepsis gegenüber den früheren Halbgöttern in Weiss hat sich der allein seligmachende Glaube an die eigene Meinung entwickelt - unterstützt und vervielfältigt in den Echokammern und Filterbubbles derjenigen, die diese Meinung teilen.

Ich kann gut verstehen, dass man darüber als Arzt oder Psychologin manchmal zu verzweifeln droht. Wenn die eigene, begründete Überzeugung konterkariert wird von all denjenigen, die ihre subjektiven Erfahrungen, spontanen Empfindungen und emotionalen Reaktionen ins Netz einspeisen. Und wenn im Namen der Selbstermächtigung und der Autonomie jeder und jede ein Recht auf eine eigene - gleichwertige - Position haben soll.

Und so besucht meine Freundin Seiten und Chatrooms, Infoseiten und Selbsthilfegruppen. Sie setzt sich auseinander mit den Hotspots der Verschwörungstheorien und der Wissenschaftskritiker. Und versucht, gleichermassen selbstkritisch wie überzeugend $\mathrm{zu}$ bleiben. Im Wissen darum, dass es nicht genügt, recht zu haben. Man muss die Menschen auch erreichen.

Dass hier all die unglaublich engagierten und überzeugten Co-Expertinnen oft sehr viel höher punkten, spornt sie an, ebenso bei den Leuten bleiben zu wollen. Im persönlichen Gespräch natürlich, aber auch im wilden weiten Internet. 